\title{
Non-medical financial burden in tuberculosis care: a cross-sectional survey in rural China
}

Qiang Li1*, Weixi Jiang², Quanli Wang ${ }^{1}$, Yuan Shen ${ }^{1}$, Jingyuan Gao ${ }^{1}$, Kaori D. Sato ${ }^{3}$, Qian Long ${ }^{2,3}$ and Henry Lucas ${ }^{4}$

\begin{abstract}
Background: Treatment of tuberculosis (TB) in China is partially covered by national programs and health insurance schemes, though TB patients often face considerable medical expenditures. For some, especially those from poorer households, non-medical costs, such as transport, accommodation, and nutritional supplementation may be a substantial additional burden. In this article we aim to evaluate these non-medical costs induced by seeking TB care using data from a large scale cross-sectional survey.

Methods: A total of 797 TB cases from three cities were randomly selected using a stratified cluster sampling design. Inpatient medical costs, outpatient medical costs, and direct non-medical costs related to TB treatment were collected using in-person interviews by trained interviewers. Mean and median non-medical costs for different sub-groups were calculated and compared using Kruskal-Wallis and Mann-Whitney $U$ tests. Regression analysis was conducted to assess the influence of different patient characteristics on total non-medical cost.

Results: The median non-medical cost was RMB 1429, with interquartile range RMB 424-2793. The median non-medical costs relating to inpatient treatment, outpatient treatment, and additional nutrition supplementation were RMB 540, 91, and 900, respectively. Of the 797 cases, $20 \%$ reported catastrophic expenditure on non-medical costs. Statistically significant differences were detected between different cities, age groups, geographical locations, inpatient/outpatient care, education levels and family income groups.
\end{abstract}

Conclusions: Non-medical costs relating to TB treatment are a serious financial burden for many TB patients. Financial assistance that can limit this burden is urgently needed during the treatment period, especially for the poor.

Keywords: Non-medical cost, Financial burden, Tuberculosis, China

\section{Multilingual abstracts}

Please see Additional file 1 for translations of the abstract into the six official working languages of the United Nations.

\section{Background}

China has the second largest burden of tuberculosis (TB) in the world, accounting for $12 \%$ of all cases [1]. Although China more than halved its TB prevalence rate from 1990 to 2010 [2], the rate remained high at the end of this period, at 459 per 100,000 for a population over

\footnotetext{
*Correspondence: tjlq@mail.xjtu.edu.cn

'Department of Biostatistics and Epidemiology, School of Public Health, Xi'an Jiaotong University, Xi'an, Shaanxi, China

Full list of author information is available at the end of the article
}

15 years old, implying significant social and economic burdens [3]. Prevalence rates are higher in poor, rural areas [4] and the poor have less access to TB care and are less likely to be cured [5]. Substandard living conditions, underlying health problems, malnourishment, a lack of money to pay for health care and inadequate access to health services all play major roles in impeding the successful treatment of TB [6].

The cost of inpatient treatment of TB in China is partly funded by health insurance schemes for those enrolled, and outpatient treatment is funded by China's national TB control program [7]. Although out of pocket (OOP) payments may also be partially reimbursed by local programs in some areas, patients must meet the largest share of outpatient care expenditures [8]. A 
number of studies have found that the financial burden relating to treatment was the most cited reason for default [9], and that non-medical costs constituted a substantial portion of this burden [10]. Treatment typically lasts six months and patients make six trips to their outpatient clinics, potentially incurring travel and accommodation costs during treatment. While this is the standard number of visits, a full course of treatment may be delivered with a minimum of four visits where patients live a considerable distance from the facility. These non-medical costs typically include payments for transport, accommodation, and the cost of nutritional supplementation during the treatment period.

Previous international studies have examined the financial burden of non-medical costs and their impact on adherence to treatment. One systematic review of overall costs for TB patients has shown that nonmedical cost accounted on average for $20 \%$ of total expenditure [11]. Other studies have found that some TB patients may be discouraged from seeking care or adhering to treatment plans by non-medical costs $[12,13]$. Transport and accommodation costs are most often considered, but one study of hospitalization for TB in Ghana, Vietnam, and the Dominican Republic indicates the substantial burden of additional food costs during treatment [14]. In China, while numerous studies have investigated the financial burden on $\mathrm{TB}$ patients [15-18], some others have focused on non-medical costs or the factors that influence them $[16,19]$, such as residence location, gender, age, inpatient versus outpatient care, health insurance status, education level, family income, and patient category.

Here, a large-scale cross-sectional survey in three Chinese cities was used to assess the non-medical financial burden on TB patients relating to expenditures on transportation, accommodation and supplementary nutrition. We also analyzed the factors influencing these expenditures.

\section{Methods}

We designed and conducted a cross-sectional survey in TB patients. In China, the administrative demarcations move downward from country to provinces to prefectures/cities to districts/counties and to towns. The study was undertaken in Zhenjiang City, Jiangsu Province in eastern China; Yichang City, Hubei Province in central China; and Hanzhong City, Shaanxi Province in western China. Sample size calculations indicated that a minimum of 792 TB cases (264 in each city) were necessary as the assumed sample proportion of catastrophic expenditure on non-medical costs were $20 \%$, with $5 \%$ as half the width of the confidence interval, and $\alpha=0.05$. In each city one county/district was randomly selected by a random number from each category of those with high, middle and low GDP per capita. Three townships/streets were then selected at random in each selected county/district and thirty $\mathrm{TB}$ cases were randomly selected from each township/ street using a list of registered cases. Patients who completed normal treatment or stopped treatment during 2012 were included in the study. We excluded patients with communication barriers, such as those with hearing impairments. We also excluded patients with serious diseases and migrant workers who did not join the survey within the study period. Patients with mental illnesses were excluded as well. In total, 797 TB patients were recruited and informed consent of each participant was obtained.

Interviews were conducted by trained enumerators using a structured questionnaire to collect the medical and non-medical costs (transportation, accommodation, and nutritional supplementation) of TB treatment. Information regarding personal demographic and socioeconomic status (age, sex, education, family income/ expenditure, etc.; Table 1), reimbursements from health insurance, and financial assistance from government agencies was also collected. The field survey was conducted between April 2013 and May 2013.

Only patients with a 'confirmed' TB diagnoses were included. Most had at least one sputum smear test and one chest $\mathrm{x}$-ray. Indirect expenditures on transport and accommodation incurred by patients, their families and others related to seeking and accessing $\mathrm{TB}$ treatment during pre-diagnostic, diagnostic and post-diagnostic periods, as well as during hospitalization where applicable, were recalled by patients and their caregivers,. The cost for nutritional supplementation during $\mathrm{TB}$ treatment was estimated by extracting the cost of extra food expenditure (such as meat, milk, vitamins, etc.). We attempted to minimize the recall bias via in-depth interviews with the patient.

Ethical approval was sought and granted for this research by the Ethical Committee of China CDC. It was recognized that the right and the welfare of the subject were adequately protected; the potential risks were outweighed by the potential benefits. The ethical approval number was 201307.

\section{Statistical analysis}

We quantified non-medical costs by aggregating the transport, accommodation, and nutritional supplementation expenditures related to TB health care. Overall, 752 patients reported complete non-medical costs for transport, accommodation, and nutritional supplementation, while others missed some portion of the above. Cases with missing data were deleted when analyzing the corresponding costs. Mean and median non-medical 
Table 1 Basic characteristics of TB patients according to study site ${ }^{a}$

\begin{tabular}{|c|c|c|c|c|c|}
\hline \multicolumn{2}{|l|}{ Characteristic } & Hanzhong & Yichang & Zhenjiang & Total \\
\hline \multicolumn{2}{|c|}{ Age in year, (Mean $\pm S D^{b}$, years) } & $55.8 \pm 14.4$ & $53.6 \pm 15.0$ & $59.3 \pm 14.7$ & $56.2 \pm 14.9$ \\
\hline \multirow[t]{2}{*}{ Sex } & Male & $211(78.1)$ & $191(72.3)$ & $192(73.0)$ & $594(74.5)$ \\
\hline & Female & $59(21.9)$ & $73(27.7)$ & $71(27.0)$ & $203(25.5)$ \\
\hline \multicolumn{2}{|c|}{ Family size, (Mean \pm SD, people) } & $3.1 \pm 1.4$ & $3.0 \pm 1.4$ & $3.4 \pm 1.7$ & $3.2 \pm 1.5$ \\
\hline \multirow[t]{2}{*}{ Area } & Rural & $252(93.3)$ & $249(94.3)$ & $235(89.4)$ & $736(92.3)$ \\
\hline & Urban & $18(6.7)$ & $15(5.7)$ & $28(10.6)$ & $61(7.7)$ \\
\hline \multirow[t]{4}{*}{ Patient category } & New patient & $218(80.7)$ & $227(86.0)$ & $193(73.4)$ & $638(80.1)$ \\
\hline & Relapse patient & $43(15.9)$ & $37(14.0)$ & $68(25.9)$ & $148(18.6)$ \\
\hline & Failure of previously untreated patient & $5(1.9)$ & $0(0.0)$ & $2(0.8)$ & $7(0.9)$ \\
\hline & Failure of re-treated patient /chronic & $4(1.5)$ & $0(0.0)$ & $0(0.0)$ & $4(0.5)$ \\
\hline \multirow[t]{4}{*}{ Education } & Never attended school & $75(27.8)$ & $30(11.4)$ & $58(22.1)$ & $163(20.5)$ \\
\hline & Primary school & $85(31.5)$ & $91(34.5)$ & $86(32.7)$ & $262(32.9)$ \\
\hline & Junior high school or at the same level & $89(33.0)$ & $96(36.4)$ & $84(31.9)$ & $269(33.8)$ \\
\hline & High school or at the same level & $21(7.8)$ & $47(17.8)$ & $35(13.3)$ & $103(12.9)$ \\
\hline \multirow[t]{2}{*}{ Health insurance } & With health insurance & $267(98.9)$ & $260(98.5)$ & $257(97.7)$ & $784(98.4)$ \\
\hline & Without health insurance & $3(1.1)$ & $4(1.5)$ & $6(2.3)$ & $13(1.6)$ \\
\hline \multicolumn{2}{|c|}{ Family income, (Median (P25-P75 $\left.{ }^{\mathrm{b}}\right), \mathrm{RMB} 1000^{\mathrm{c}}$ ) } & $15.0(5.0-30.0)$ & $20.0(9.2-32.6)$ & $36.0(13.0-63.6)$ & $21.4(7.6-40.0)$ \\
\hline \multicolumn{2}{|c|}{ Family expenditure, (Median (P25-P75 $)$, RMB 1000 ) } & $15.0(7.5-23.5)$ & $20.0(9.0-30.0)$ & $20.0(10.0-35.0)$ & $20.0(9.8-30.0)$ \\
\hline
\end{tabular}

${ }^{\mathrm{a}}$ Data are $\mathrm{n}(\%)$ unless otherwise indicated. TB: tuberculosis

${ }^{\mathrm{b}} \mathrm{SD}$ : standard deviation. P25: $25^{\text {th }}$ percentile. P75: $75^{\text {th }}$ percentile

${ }^{C}$ RMB 1000: a currency exchange rate of Chinese RMB 628 Yuan to US\$100 Yuan at the end of 2012,RMB1000 = US\$159

expenditures were calculated and compared across subgroups using Mann-Whitney $U$ and Kruskal-Wallis tests and a $5 \%$ significance level. Linear regression was then used to model the relationships between non-medical costs and the explanatory variables available from the survey data. We also separated the transport plus accommodation costs and the additional nutrition cost for the multi-variate analysis. All the statistical analysis was done using the SAS version 9.3 statistical software package (SAS Institute Inc., Cary, North Carolina).

We considered the following patient variables to be potentially correlated with non-medical costs as they were major risk factors for the non-medical cost: residence location (the three study cities), gender, age ( $<65$ years or $>=65$ years), residence type (urban or rural), inpatient care (with or without), health insurance (covered or uncovered), education level (never attended school, primary school, junior high school, high school or higher), family income (as a proportion of the median in each city), and patient category (new or relapse patient).

\section{Results}

Table 1 shows the basic demographic characteristics of the participants. In total, $797 \mathrm{~TB}$ patients were included in the study, with mean ages ranging from 53.6 to 59.3 across the three study sites. Some $74.5 \%$ were male, and $80.1 \%$ were new patients. Most came from rural areas, and their degree of education was limited. Overall onefifth (almost $28 \%$ in Hanzhong) had no formal education. Only $12.9 \%$ of the participants had received a high school education or similar. The average family income was RMB 21,400 (equaling to US\$3408, a currency exchange rate of Chinese RMB 628 Yuan to US\$100 at the end of 2012), ranging from RMB 15,000 (US\$2389) in Hanzhong to RMB 36,000 (US\$5732) in Zhenjiang. It was notable that the average family expenditure (RMB 20,000) was almost equal to the average income, indicating that many families would have very limited ability to save. As expected, given the government promotion of the urban and rural health insurance schemes, almost all patients were covered by one of these schemes. The largest percentage $(41.9 \%)$ of participants made six trips to their outpatient clinic during treatment, potentially incurring travel and accommodation costs.

As shown in Table 2, non-medical financial costs related to TB treatment varied considerably across study sites. The overall mean and median expenditure was considerably lower in Yichang than in Hanzhong and Zhenjiang. However, this was a simply reflection of the 
Table 2 Non-medical financial cost related to TB treatment by study site $\left(R^{2} B^{\mathrm{a}}\right)$

\begin{tabular}{|c|c|c|c|c|c|c|c|c|c|c|c|c|c|}
\hline & \multirow[t]{2}{*}{$\mathrm{n}$} & \multicolumn{3}{|c|}{ Hanzhong } & \multicolumn{3}{|c|}{ Yichang } & \multicolumn{3}{|c|}{ Zhenjiang } & \multicolumn{3}{|l|}{ Total } \\
\hline & & Mean & Median & $P 25-P 75^{b}$ & $\overline{\text { Mean }}$ & Median & P25-P75 & Mean & Median & P25-P75 & Mean & Median & P25-P75 \\
\hline Total & $752^{c}$ & 2308 & 1785 & $853-3185$ & 1453 & 968 & $318-1880$ & 2061 & 1800 & $381-3000$ & 1943 & 1429 & $424-2793$ \\
\hline Inpatient & 371 & & & & & & & & & & & & \\
\hline Travel fee & & 130 & 30 & $10-100$ & 257 & 50 & $20-270$ & 124 & 15 & $0-100$ & 158 & 30 & $6-120$ \\
\hline Accommodation fee & & 822 & 530 & $150-1060$ & 1018 & 760 & $300-1350$ & 547 & 315 & $108-630$ & 766 & 500 & $150-1000$ \\
\hline Subtotal & & 958 & 600 & $210-1240$ & 1285 & 815 & $350-1710$ & 673 & 400 & $200-823$ & 928 & 540 & $208-1200$ \\
\hline Outpatient & 753 & & & & & & & & & & & & \\
\hline Travel fee & & 98 & 60 & $24-120$ & 150 & 120 & $40-204$ & 77 & 28 & $0-96$ & 109 & 60 & $12-140$ \\
\hline Accommodation fee & & 124 & 30 & $0-100$ & 56 & 20 & $0-75$ & 20 & 0 & $0-0$ & 68 & 0 & $0-60$ \\
\hline Subtotal & & 223 & 91 & $30-240$ & 206 & 144 & $60-270$ & 97 & 36 & $0-120$ & 176 & 91 & $20-210$ \\
\hline Additional nutrition fee & 770 & 1586 & 1200 & $300-2400$ & 828 & 435 & $0-1200$ & 1596 & 1200 & $0-2400$ & 1337 & 900 & $0-1800$ \\
\hline
\end{tabular}

${ }^{\mathrm{a}} \mathrm{RMB}$ 1000: a currency exchange rate of Chinese RMB 628 Yuan to US\$100 Yuan at the end of 2012, RMB1000 $=$ US\$159

b25: $25^{\text {th }}$ percentile. P75: $75^{\text {th }}$ percentile

'The total non-medical cost is the sum of the inpatient cost, outpatient cost and the additional nutrition fee. The total number of patients is less than that in the subgroup because of missing data

much more limited expenditure on supplementary nutrition - around half that in the other cities. Both travel and accommodation costs were substantially higher in Yichang, which was probably a reflection of the increased distance that patients had to travel to a designated TB facility.

Table 3 reveals the non-medical economic burden of TB care, as measured by the numbers/proportions of patients with catastrophic health care expenditure on care. Overall, some $20 \%$ of all respondents reported that their non-medical costs exceeded $40 \%$ of their non-food expenditure, while $37 \%$ reported that these costs exceeded $10 \%$ of their annual household income. The nonmedical burden was highest in Hanzhong using both measures.

Table 4 shows the influence of different patient characteristics on total non-medical costs. In addition to the variation between the study cities, the relationships between non-medical costs and age group, residence type (urban/rural), receiving inpatient care, education and family income were statistically significant.

The results of the regression analysis are reported in Table 5. In this analysis we combined transportation and accommodation costs as both are related to geographic factors such as distance from home to facility and availability of transportation options. The table indicates that after controlling for other variables, living in Yichang was still associated with higher transportation and accommodation costs and lower additional nutrition costs. For transportation and accommodation costs specifically, only care type and age were likely to have a significant influence in addition to city of residence. However, additional nutrition costs were also positively correlated with higher education level, family income and urban residence.

Table 3 Description of the non-medical burden of TB health care, $n$ (\%)

\begin{tabular}{|c|c|c|c|c|c|}
\hline Non-medical cost in TB health care & Hanzhong & Yichang & Zhenjiang & Total & $P_{\text {_value }}{ }^{\mathrm{a}}$ \\
\hline$\geq 40 \%$ of the annual capacity to pay & $65(26.9)$ & $29(11.9)$ & $51(21.2)$ & $145(20.0)$ & $<0.011$ \\
\hline$\geq 10 \%$ of the annual household income & $132(52.4)$ & $81(32.7)$ & $62(25.3)$ & $275(36.9)$ & $<0.011$ \\
\hline \multicolumn{6}{|l|}{ Groups of non-medical cost (RMB) } \\
\hline$\leq 200$ & $35(13.8)$ & $45(18.1)$ & $53(21.3)$ & $133(17.7)$ & \multirow[t]{6}{*}{$<0.011$} \\
\hline $201 \sim 1000$ & $45(17.7)$ & $82(32.9)$ & $31(12.4)$ & $158(21.0)$ & \\
\hline $1001 \sim 2000$ & $64(25.2)$ & $64(25.7)$ & $60(24.1)$ & $188(25.0)$ & \\
\hline $2001 \sim 4000$ & $66(26.0)$ & $38(15.3)$ & $70(28.1)$ & $174(23.1)$ & \\
\hline $4001 \sim 6000$ & $29(11.4)$ & $14(5.6)$ & $26(10.4)$ & $69(9.2)$ & \\
\hline$\geq 6001$ & $15(5.9)$ & $6(2.4)$ & $9(3.6)$ & $30(4.0)$ & \\
\hline
\end{tabular}

${ }^{a}$ Chi-square test was used to compare the difference of percentage between study sites 
Table 4 Comparison of non-medical cost of TB care between different characteristics, RMB

\begin{tabular}{|c|c|c|c|}
\hline Characteristic & Mean & Median & $P_{\text {_value }}{ }^{a}$ \\
\hline City & & & $<0.001$ \\
\hline Hanzhong & 2308 & 1785 & \\
\hline Yichang & 1453 & 968 & \\
\hline Zhenjiang & 2060 & 1800 & \\
\hline Sex & & & 0.445 \\
\hline Men & 1940 & 1410 & \\
\hline Women & 1950 & 1470 & \\
\hline Age & & & $<0.001$ \\
\hline$<65$ years & 2163 & 1605 & \\
\hline$>=65$ years & 1490 & 1050 & \\
\hline Residence type & & & $<0.001$ \\
\hline Urban & 3128 & 2600 & \\
\hline Rural & 1842 & 1320 & \\
\hline Inpatient care & & & $<0.001$ \\
\hline With & 2567 & 2115 & \\
\hline Without & 1370 & 900 & \\
\hline Health insurance & & & 0.889 \\
\hline Covered & 1794 & 1495 & \\
\hline Uncovered & 1945 & 1429 & \\
\hline Education & & & $<0.001$ \\
\hline Never attended school & 1389 & 1040 & \\
\hline Primary school & 1864 & 1268 & \\
\hline Junior high school & 2146 & 1658 & \\
\hline High school or higher & 2479 & 1837 & \\
\hline Family income & & & $<0.001$ \\
\hline Lower half & 1560 & 1066 & \\
\hline Higher half & 2298 & 1700 & \\
\hline Category & & & 0.540 \\
\hline New patient & 1884 & 1406 & \\
\hline Relapse patient & 2182 & 1600 & \\
\hline
\end{tabular}

${ }^{\text {a }} P_{-}$value was calculated by univariate analysis

\section{Discussion}

China's national TB control program requires patients to visit the TB outpatient clinic every month for six months or at least four times during the first, second, fifth and last month of the treatment regimen [20]. A majority of participants in this study adhered to this requirement, although many of them suffered from heavy financial burden caused by TB treatment. In many cases, especially where patients lived in more remote areas - which were typically associated with lower household incomes this entailed considerable expenditure on travel and accommodation, leading to non-medical expenditures that may be comparable to out-of-pocket payments for hospitalization.
Non-medical costs of TB treatment placed a considerable financial burden on patients. Some $25 \%$ of participants spent RMB $1001 \sim 2000$ on non-medical costs while over $23 \%$ spent RMB $2001 \sim 4000$. These costs were considerable when compared to household expenditures, which ranged from RMB 15,000 to 20,000 across the three cities, and to incomes, which ranged from RMB 15,000 to 36,000 .

Inpatient care was positively associated with both types of costs $(P<0.05)$, which can be explained by the fact that receiving inpatient care increased the accommodation costs for patients and their companions, and the likelihood of purchasing additional food during hospitalization. The negative impacts of higher age on both cost components may be ascribed to older people's limited ability to travel to health facilities (especially for patients in remote areas) and to their lower willingness and capacity to pay for additional food. This is consistent with results from previous studies which revealed that older people do not want use their children's money for treatment as they believe the money could be used for more meaningful purposes, for example, the education of their grandchildren [16, 21].

The impact of other patient characteristics on nonmedical costs were mixed for the two types of costs. Geographic constraints played a major role in the influence of location on costs, as Yichang and Hanzhong have vast mountainous areas, which increases travel costs and adds to the difficulty of purchasing additional food. Indicators of socio-economic status - residence type, education and family income - were all positively associated with additional nutrition costs but had no significant influence on travel and accommodation costs. This would suggest that patients with higher levels of education, a greater ability to pay and wider availability of nutritional supplements (in urban areas) were more willing and able to consume more nutritious foods to help with recovery.

The results of the regression analyses revealed the different nature of the two types of non-medical costs, and suggested how to reduce patient costs in following the prescribed treatment regimen. Future policies might best serve to focus on reducing travel and accommodation costs, which have the greatest impact on poorer households in remote areas. One study has confirmed the role of transportation subsidies in reducing the financial burden of TB patients but suggests that the amount provided needs to be more substantial [19, 22]. Our study indicates that geographic factors exert such a major influence on non-medical costs that the amount of travel subsidy should be determined by location of residence. Additional subsidies may also be appropriate to encourage adherence to treatment by older patients. For the 
Table 5 Regression analysis of total non-medical cost and patient characteristics ${ }^{a}$

\begin{tabular}{|c|c|c|c|c|c|c|c|c|c|c|}
\hline \multirow[t]{2}{*}{ Variable } & & \multicolumn{3}{|c|}{ Total non-medical cost } & \multicolumn{3}{|c|}{ Transportation plus accommodation cost } & \multicolumn{3}{|c|}{ Additional nutrition cost } \\
\hline & & Parameter & SE & $P$ value & Parameter & SE & $P$ value & Parameter & SE & $P$ value \\
\hline \multicolumn{11}{|l|}{ Location } \\
\hline Hanzhong & & 8.00 & 1.86 & $<.0001$ & -1.98 & 1.19 & 0.0970 & 13.31 & 2.02 & $<.0001$ \\
\hline Yichang & Ref & & & & & & & & & \\
\hline Zhenjiang & & 4.45 & 1.86 & 0.0167 & -6.42 & 1.19 & $<.0001$ & 10.87 & 2.02 & $<.0001$ \\
\hline Sex & Ref: male & 2.66 & 1.73 & 0.1241 & 0.40 & 1.11 & 0.7203 & 2.31 & 1.89 & 0.2209 \\
\hline age & Ref: aged $<65$ & -6.12 & 1.70 & 0.0003 & -2.38 & 1.08 & 0.0285 & -5.24 & 1.84 & 0.0046 \\
\hline Residence type & Ref: rural & 10.18 & 2.82 & 0.0003 & -0.62 & 1.83 & 0.7356 & 11.35 & 3.05 & 0.0002 \\
\hline Inpatient care & Ref: without & 14.86 & 1.50 & $<.0001$ & 18.53 & 0.96 & $<.0001$ & 4.00 & 1.62 & 0.0140 \\
\hline Health insurance & Ref: covered & 7.12 & 5.91 & 0.2290 & 6.88 & 3.84 & 0.0737 & 1.86 & 6.22 & 0.7657 \\
\hline \multicolumn{11}{|l|}{ Education } \\
\hline Never attended school & Ref & & & & & & & & & \\
\hline Primary school & & 6.22 & 2.15 & 0.0040 & 0.31 & 1.37 & 0.8197 & 6.47 & 2.33 & 0.0057 \\
\hline Junior high school & & 7.32 & 2.24 & 0.0011 & 1.36 & 1.43 & 0.3432 & 6.49 & 2.44 & 0.0079 \\
\hline High school or higher & & 9.19 & 2.90 & 0.0016 & 0.27 & 1.84 & 0.8815 & 9.25 & 3.15 & 0.0034 \\
\hline Family income & Ref: lower half & 4.12 & 1.57 & 0.0090 & 0.45 & 1.00 & 0.6517 & 6.16 & 1.70 & 0.0003 \\
\hline Category & Ref: new patients & 1.61 & 1.87 & 0.3891 & -1.54 & 1.19 & 0.1983 & 2.69 & 2.02 & 0.1838 \\
\hline
\end{tabular}

${ }^{a}$ Following variables were enrolled in the regression medel: residence location (the three study cities), gender, age (<65 years or $>=65$ years), residence type (urban or rural), inpatient care (with or without), health insurance (covered or uncovered), education level (never attended school, primary school, Junior high school, high school or higher), family income (as a proportion of the median in each city), and patient category (new or relapse patient)

effect of health insurance, our results were similar to a previous study which indicated higher non-medical costs for those not covered by any health insurance [16].

This study is not without its limitations. Firstly, investigators were trained to extract information as reliably as possible. However, the recall bias of annual income and non-direct medical costs can hardly be avoided due to the long treatment duration. Patients' estimation of transportation, accommodation and additional food costs may not be accurate. Secondly, some patients received therapy mainly in 2011 and so major non-medical costs were incurred in 2011; however, these patients reported their 2012 income which may not have reflected their economic statuses during treatment when incomes may have been reduced. In addition, only three cities form eastern China, central China and western China were selected by location instead of by TB burden level. Cities with the highest TB burden, such as Tibet, Xinjiang and Guizhou, were not involved. Thus, the present results were limited when considering TB burden levels. Future studies on the economic burden of non-medical costs could gather more accurate information through timely monitoring during treatment in broader areas.

\section{Conclusion}

Non-medical costs related to TB treatment imposed a considerable financial burden for $\mathrm{TB}$ patients, often accounting for a considerable proportion of their annual income. Geographic factors played such an important role in transportation and accommodation costs that transportation subsidies should be provided based on the patients' places of residence.

\section{Additional file}

Additional file 1: Multilingual abstracts in the six official working languages of the United Nations. (PDF $542 \mathrm{~kb}$ )

Abbreviations

GDP: Gross Domestic Product; OOP: Out-of-Pocket payment; TB: Tuberculosis.

Competing interests

The authors declare that they have no competing interests.

\section{Authors' contributions}

QL developed the study concepts, analyzed the data, and prepared the manuscript. He had full access to all the data of the study and was responsible for the integrity of the data and the accuracy of the data analysis. WJ, QW, YS, JG, KDS and QL participated in the field study, interpreted and commented on the manuscript. $\mathrm{HL}$ participated in the interpretation of findings and paper editing. All authors read and approved the final manuscript.

\section{Acknowledgments}

The study upon which this paper was written is part of the large program entitled "China National Health and Family Planning Commission and the Gates Foundation TB Project" - a collaboration between the Government of China and the Bill and Melinda Gates Foundation (Grant No. 51914), and implemented by the China Center of Disease Control and Prevention (CDC). The Duke Global Health Institute, USA/Duke Kunshan University in China, 
and Nanjing Medical University, Huazhong University of Science and Technology and Xi'an Jiaotong University in China were contracted by the Foundation and China CDC to undertake the baseline survey, and monitoring and evaluation of innovative financial models of TB/MDRTB control and care in China. The authors are also grateful for the supports and valuable comments provided by Prof. Shenglan Tang, Duke Global Health Institute.

\section{Author details}

'Department of Biostatistics and Epidemiology, School of Public Health, Xi'an Jiaotong University, Xi'an, Shaanxi, China. ${ }^{2}$ Global Health Research Center, Duke Kunshan University, Kunshan, Jiangsu, China. ${ }^{3}$ Duke Global Health Institute, Duke University, Durham, NC, USA. ${ }^{4}$ Institute of Development Studies at the University of Sussex, Brighton, UK.

Received: 24 August 2015 Accepted: 26 December 2015

Published online: 26 January 2016

\section{References}

1. WHO. Global tuberculosis report 2014. Geneva: World Health Organization; 2014.

2. Wei X, Zou G, Walley J, Yin J, Lonnroth K, Uplekar M, et al. China tuberculosis policy at crucial crossroads: comparing the practice of different hospital and tuberculosis control collaboration models using survey data. PLoS One. 2014:9(3):e90596. doi:10.1371/journal.pone.0090596.

3. Technical Guidance Group of the Fifth National TB Epidemiological Survey, The Office of the Fifth National TB Epidemiological Survey. The fifth national tuberculosis epidemiological survey in 2010. Chin J Antituberc. 2012;34(8):485-508.

4. WHO. Global tuberculosis control: epidemiology, strategy, financing. Geneva: World Health Organization; 2009.

5. World Health Organization. Tackling poverty in tuberculosis control. Lancet. 2005;366(9503):2063. doi:10.1016/S0140-6736(05)67862-2.

6. Yao H, Wei X, Liu J, Zhao J, Hu D, Walley JD. Evaluating the effects of providing financial incentives to tuberculosis patients and health providers in China. Int J Tuberc Lung Dis. 2008:12(10):1166-72.

7. Li W, Li X, Zhang H, Li R, Cheng J, Wang L. Investigation on the current health insurance status of pulmonary tuberculosis cases without drug resistance in certain areas of China. Chin Prev Med (in Chinese). 2012;13(6):401-5.

8. Liu Q, Smith H, Wang Y, Tang S, Wang Q, Garner P. Tuberculosis patient expenditure on drugs and tests in subsidised, public services in China: a descriptive study. Trop Med Int Health. 2010;15(1):26-32. doi:10.1111/j.13653156.2009.02427.x

9. Long Q, Smith H, Zhang T, Tang S, Garner P. Patient medical costs for tuberculosis treatment and impact on adherence in China: a systematic review. BMC Public Health. 2011;11:393. doi:10.1186/1471-2458-11-393.

10. Liu X, Thomson R, Gong Y, Zhao F, Squire SB, Tolhurst R, et al. How affordable are tuberculosis diagnosis and treatment in rural China? An analysis from community and tuberculosis patient perspectives. Trop Med Int Health. 2007:12(12):1464-71. doi:10.1111/j.1365-3156.2007.01953.x.

11. Tanimura T, Jaramillo E, Weil D, Raviglione M, Lonnroth K. Financial burden for tuberculosis patients in low-and middle-income countries: a systematic review. Eur Respir J. 2014;43(6):1763-75. doi:10.1183/09031936.00193413.

12. Chen C, Liu J, Yao H. Economic and geographic factor analysis for cases with limited access to health service in Hubei FIDELIS area. Chin J AntiTuberculosis. 2007;29(4):293-7.

13. Shargie EB, Lindtjorn B. Determinants of treatment adherence among smear-positive pulmonary tuberculosis patients in Southern Ethiopia. PLoS Med. 2007;4(2):e37. doi:10.1371/journal.pmed.0040037.

14. Nhung NV, Bonsu F, Suarez P, Gyapong M, Hoa NB, Awini E, et al. Free tuberculosis diagnosis and treatment are not enough: patient cost evidence from three continents. Int J Tuberc Lung Dis. 2013;17(3):381-7. doi:10.5588/ ijtld.12.0368

15. Chen S, Zhong J, Wang X. Investigation and analysis of tuberculosis pulmonary diseases in Zhejiang Province. Chin J of PHM (in Chinese). 2014;30(2):147-9.

16. Zhang $M$, Wu W, Tong $Y$, Yang $X$, Huang W, Wu H. Family financial burden of patients with tuberculosis in Guizhou. China Prev Med (in Chinese). 2014; 15(2):114-7.
17. Li Q, Cao X, Zhao G, Zhang L, Xu L. Analysis on economic burden of disease and its influencing factors of pulmonary tuberculosis patient in Shangdong Province. Chin Health Econ (in Chinese). 2010;29(4):71-3.

18. Wang Q, Wang L, Li R, Ruan Y, Chen M, Sun Q. Analysis of the medical expenses and economic burden of pulmonary tuberculosis patients in three cities.

Chin J Antituberc (in Chinese). 2013:35(4):240-5.

19. Kun S, Lixia W, Daiyu H, Qiuyang C, Yongming L, Ying $L$, et al. A qualitative study of transport subsidy project on enabling poor TB patients to complete the treatment course. Chin Health Resour (in Chinese). 2010;13(6):280-3.

20. $\mathrm{MOH}$. China Tuberculosis Prevention and Control Plan: guideline for programme implementation. Beijing, China: Disease Control Department [in Chinese]; 2002.

21. Xu B, Fochsen G, Xiu Y, Thorson A, Kemp JR, Jiang QW. Perceptions and experiences of health care seeking and access to TB care-a qualitative study in rural Jiangsu Province. China Health Policy. 2004;69(2):139-49. doi:10.1016/j.healthpol.2003.11.006.

22. Zhao Q, Wang $L X$, Tao T, Xu B. Impacts of the "transport subsidy initiative on poor TB patients" in rural China: a patient-cohort based longitudinal study in rural China. PLoS One. 2013;8(11):e82503. doi:10.1371/journal. pone.0082503.

\section{Submit your next manuscript to BioMed Central and we will help you at every step:}

- We accept pre-submission inquiries

- Our selector tool helps you to find the most relevant journal

- We provide round the clock customer support

- Convenient online submission

- Thorough peer review

- Inclusion in PubMed and all major indexing services

- Maximum visibility for your research

Submit your manuscript at www.biomedcentral.com/submit 